Article

\title{
Automated Valuation Methods through the Cost Approach in a BIM and GIS Integration Framework for Smart City Appraisals
}

\author{
Natale Arcuri ${ }^{1}$ (D), Manuela De Ruggiero ${ }^{2, *}$, Francesca Salvo ${ }^{2}$ and Raffaele Zinno ${ }^{2}$ (D) \\ 1 Department of Mechanical, Energy and Management Engineering, University of Calabria, 87036 Rende, \\ Italy; natale.arcuri@unical.it \\ 2 Department of Environmental Engineering, University of Calabria, 87036 Rende, Italy; \\ francesca.salvo@unical.it (F.S.); raffaele.zinno@unical.it (R.Z.) \\ * Correspondence: manueladeruggiero@gmail.com; Tel.: +39-348-156-9226
}

Received: 22 July 2020; Accepted: 9 September 2020; Published: 13 September 2020

check for updates

\begin{abstract}
The principle behind sustainable city movements is represented by the idea of "good living", which is the possibility of having solutions and services that allow citizens to live in an easy, simple, and enjoyable way. Policies for urban quality play a central role in the slow cities manifesto, often suggesting the use of Information and Communication Technologies (ITC) in the development of interactive services for citizens. Among these, an interesting possibility is to offer citizens digital real estate consultancy services through the implementation of automated evaluation methods. An automated appraisal action-which is already complex in itself owing to the need to collect data in a consistent, standardized, but also differentiated way so as to require the adoption of real estate due diligence-collides on the operational level with the concrete difficulty of acquiring necessary data, much more so since the reference market is dark, atypical, and viscous. These operational difficulties are deepened by the epistemological nature of the appraisal discipline itself, which bases its methodology on the forecast postulate, recalling the need to objectify as much as possible the evaluation from the perspective of an intersubjective sharing argument. These circumstances have led, on the one hand, to the definition of internationally accepted uniform evaluation rules (IVS, 2017) and, on the other, to the testing of automated valuation methods aimed at returning computer-based appraisals (AVM). Starting from the awareness that real estate valuation refers essentially to information and georeferences, this paper aims to demonstrate how real estate appraisal analysis can be further improved through information technology (IT), directing real estate valuation towards objectivity in compliance with international valuation standards. Particularly, the paper intends to show the potential of combining geographic information systems (GISs) and building information models (BIMs) in automated valuation methods through the depreciated reproduction cost. The paper also proposes a BIM-GIS semi-automatic prototype based on the depreciated reconstruction cost through an experimentation in Rende (Italy).
\end{abstract}

Keywords: building information modeling; geographic information systems; real estate appraisal; cost approach; smart cities

\section{Introduction}

Cities of the third millennium are currently facing challenges that require intelligent solutions, which can be translated into new services for citizens. The challenges that cities are facing are producing a strong impact on their economy, competitiveness, and their own vision of the future. New solutions are necessary to guarantee citizens' safety with healthy and comfortable places to live, work, and spend their free time $[1,2]$. 
The use of technology is a fundamental and essential tool in the creation of smart but, at the same time, livable cities.

This means actually digitizing and connecting systems in order to detect, capture, and manage all the real-time information available in the area in an integrated way. The processing and redistribution of information will allow citizens to enjoy a series of assistance and information services in real time, with particular attention to citizens and public and private operators.

In this perspective, an interesting role can be played by the real estate sector, which, through the use of information technology (IT) tools, can offer important digital services for private and taxation purposes by means of automated valuation methods (AVM).

The real estate market has always been a conservative sector, in which new tools and operating methods have always struggled to establish themselves. In the past 20 years, however, technological innovations have almost completely reshaped the way we all live. The time is therefore ripe for a digital real estate revolution, which, in fact, is already underway. Thanks to data analysis and the use of digital technologies, the way in which sector specialists, agents, and real estate consultants carry out their activities, manage human resources, and optimize investments is changing: from agenda management to taking appointments, from the promotion of properties to the acquisition of new assignments, up to the definition of the correct value of a property. Moreover, in the investment decision, the price of the property remains the most important factor to be taken into consideration. Each property has its own market value, and determining the correct price is fundamental during the transaction phase: It benefits both the buyer and the seller as well as, in general, the efficiency of the property market. Real estate valuation bases its validity on the market evidence analytically represented by the appraisal function, according to which the price/value of a property is determined by the number of its real estate characteristics [3].

Each of the characteristics affects the formation of the price to a different extent according to the appreciation level that the reference market shows for each of them. The characteristics that normally determine price are of a different nature, and they can generally be classified into extrinsic position characteristics, intrinsic position characteristics, technical characteristics, and economic/production characteristics [4].

The extrinsic position characteristics are conditions external to the property; they refer more generally to the location context in terms of accessibility, services, environmental conditions, etc.

The intrinsic position characteristics, on the other hand, represent the specific conditions of the properties in terms of intended use, structure and composition, maintenance status, orientation, brightness, etc. The technical characteristics concern the degree of finishing of the building in terms of the used materials, degree of acoustic and thermal insulation, and plant characteristics. Finally, the production characteristics concern the profitability of the property in terms of rents, vacancy conditions and non-collectability, historical and environmental constraints, and others.

The nature and peculiarities of the real estate features are constantly evolving, adding new types of real estate features only little considered in the past. We are talking about variables that contribute to improving the appreciation of properties with a view to economic, social, and environmental sustainability [5]. The impact of these characteristics must also be read in the microeconomic and macroeconomic market environment made of socio-economic conditions, market form, price levels, and characteristics of supply and demand.

In compliance with the different classifications reported in literature, the numerous and heterogeneous real estate characteristics can be conceptually grouped into two distinct categories: those that have a strong territorial connotation, such as the economic-social and locational ones, and those that are detached from the reference market but related to the physical nature of the property itself (surface variables, technological systems, and maintenance state). We have to note that the values of properties are also affected by subjective variables linked to the specific characteristics of users. These variables are particularly useful where real markets are absent, allowing the reconstruction 
of hypothetical markets that can be defined, for example, through the detection of preferences and willingness to pay (contingent valuation method) [6-8].

However, in the presence of real property markets, the International Valuation Standards suggest the use of appraisal methods rather than economic ones, moving within the postulate of ordinariness and, therefore, referring the valuation to ordinary subjects characterized by statistically normal preferences detectable in the market segment.

Information technologies offer tools that are useful for representing and managing these two different types of characteristics. In particular, geographic information systems (GISs) allow one to work with spatial data modeling accurately, as well as with environmental, territorial, and locational factors, while building information models (BIMs) efficiently manage the complexity of a 3D building structure with its intrinsic features.

The present paper intends to analyze the possibility of implementing an automatic method that can be used where the applicability of market-oriented methods is lacking based on the integration of BIM and GIS technologies. More specifically, the idea is to entrust the fifth dimension of building information modeling with the appraisal of the physical real estate characteristics and to integrate it with the support of the geographic information systems technology, which is useful for analyzing the territorial features, so as to allow the automation of the calculation of the depreciated reconstruction cost (DRC). To this end, after recalling the reference literature and outlining the methodological tools, the results of a pilot study carried out in the territory of Rende (Italy) are reported.

\section{Research Background}

Information technologies have profoundly revolutionized the way to archive, organize, manage, and work with information, with important repercussions on the world of works, buildings, and infrastructures, as they unlock new ways of working for all construction disciplines $[9,10]$. Real estate appraisers, aware of the central role played by information in real estate valuation, have recently understood the potential of information technologies, preparing IT tools capable of drawing up reliable real estate appraisals based on traditional evaluative methodologies, but automatically implemented. This approach has led to so-called automated valuation methods (AVMs), tools that are able to provide real estate property valuations using mathematical modeling combined with a database. Most AVMs calculate a property's value at a specific point in time by analyzing values of comparable properties in order to essentially implement market-oriented methods. The idea of automating the sales comparison approach has appeared sporadically in real estate literature over time, and it has been used in some CAMA (computer-assisted mass appraisal) methods [11,12].

Most of the automatic methods are based on the implementation of regression models, which are useful for defining the appraisal function in homogeneous territorial areas. Detweiler and Radigan [13,14] published papers describing their Computer-Assisted Real Estate Appraisal System (CAREAS). Their work described a statistically derived dissimilarity index used to select comparables and a regression model to create adjustment factors. The use of sophisticated fitting techniques can account for different functional forms or, in some cases, the complete lack of functional relationships. Spline regressions, nonparametric regressions, and autoregressive techniques are three of such examples [15-17]. Incorporating spatial information in pricing models through the use of direct spatial modeling with Cartesian coordinates [18], geostatistical models [19,20], or response surfaces [21] has improved the precision of price estimates. Other studies [22-24] have focused on improving sample selection by delineating submarkets of homes in which the marginal price contributions of independent variables are more likely to be similar. Predicted residuals from nearby sales (spatial errors) have been used in two separate but related ways in the literature. Case et al. [25], in particular, developed a two-stage method in which errors from a single-stage ordinary least squares (OLS) model are used as predictors in the two-stage model; conversely, Pace and Gilley [26], among others, used a simultaneous auto-regressive (SAR) model to account for nearby residuals in a single-stage model. Bourassa, Hoesli, and Cantoni $[27,28]$ recently dealt with uses of autoregressive models. 
The application of the International Valuation Standards has prompted research to investigate the possibility of applying AVMs even in really complex real estate markets for different issues that are at stake, including best practices, real-life constraints, administrative procedures, software capabilities, expert competences, modeling frameworks, background theories, and more [29-31].

A central role in the modeling of automatic methods is played by geographic information systems because of their ability to manage spatial data, relating information from different sources by space-time location and, therefore, correlating different levels of information. GISs have the ability to manage a large quantity of data, allowing implementation of mass appraisal methods [32], analysis of real estate features [33], and improvement of the quality of real estate appraisals [34]; moreover, they are useful for creating databases of comparables that are ready to apply market-oriented procedures in AVMs [35-38].

Over the past decade, the construction and infrastructure sector has been hit by another major change linked to the advent of building information models (BIMs), which emerged to govern the process of building in its various phases, and have also proved particularly useful in the economic declination represented by the fifth dimension, that of quantifying costs, thus drawing the attention of appraisers. Building cost appraisal is essential for budgeting and tendering in any construction project. It reflects the inherent risks and direct costs of a project involving materials, labor, professional services, etc. [39]. Inevitably, BIMs mean changes to the way cost plans and estimates are produced as well. Lu et al. [40] and Underwood and Isikdag [41] claim that BIMs have the potential to increase efficiency. Five-dimensional BIMs offer the capabilities of generating takeoffs, counts, and measurements directly from a model, providing efficiencies for quantity surveyors, and providing more reliable cost advice [42,43]. From the quantity surveyor point of view, the capability of BIMs of automating measurement is their key benefit, and it clearly speeds up the traditional estimating process. It is evident that BIMs deliver a more efficient operational solution for the quantity surveyors for cost estimation with their ability to link the relevant quantities and cost information to the digital building model cycle. We have to note that the ability of BIM platforms to perform automated quantification of items, areas, and volumes of building elements does not produce a cost appraisal, but just an automatic quantity survey. Application of BIMs in cost estimation is a broader process than mere automated measurements. Eastman et al. [44] suggest several approaches for BIM-based cost estimation, such as exporting building object quantities to estimating software (usually MS Excel format), although Hardin [10] argues that it is inefficient to export the quantities if the BIM model and the spreadsheet or database are not linked in a way that the latter is automatically updated with the changes to the former. Again, it is possible to bridge the BIM tool directly with estimation software that is directly linked to the BIM design tools [45]. Another approach is to use BIM quantification tools in order to transfer the BIM models and their embedded information from BIM design tools into specialized Quantity TakeOff (QTO) software, an approach that provides an advantage for the quantity surveyors to work using familiar QTO software without having to possess an in-depth understanding of BIM design platforms [46].

In this way, BIMs have been widely used in economic analysis related to building lifecycle costs [47-50]. Some research has been done about the use of BIMs in property valuations. Yamani et al. experimented with a prototype based on the hedonic price method in order to enhance real estate valuation [51]. Yu and Liu are among the first to experiment with the integration of GIS and BIM for real estate valuation [52].

The use of BIM technologies in the field of real estate appraisals and, in particular, its integration with GIS for estimation purposes is, however, still in the embryonic stage, but due to the characteristics of these tools, the existence of interesting research prospects can be foreseen. This paper tries to make a different contribution in the field of automated valuation methods. 


\section{Methods}

Properties are, in general, heterogenous and unique, so that their prices/market values are determined by many features, both territorial and physical $[53,54]$, which have to be detected in a standardized and consistent way [55]. According to the availability of data and to the appraisal criterion, the evaluator can choose between the different valuation methods reported in the literature [56].

When large amounts of sales data are available, the choice is usually to fall back on market-oriented procedures. In the market approach, the idea consists of interpreting the mechanism of formation of real estate prices (historical data) to predict future real estate values (probabilistic data) on the basis of the comparison between the real estate features.

When comparable sales data are not available or not consistent enough to apply a market-oriented method, the appraiser has to use a Cost Approach, which is based on the idea that the buyer is not willing to spend more on a property than it would cost them to rebuild it as it is, taking into account the state of maintenance and use.

Finally, when the evaluation concerns properties for which the aspect of income prevails over that of the capital value, the choice may fall on financial methods, such as those referable to the Income Approach.

When data are consistent and available in a real estate database, it is possible to implement automated valuation methods. Automated methods, traditionally proposed at the international level, are often set on multiple regression models and are designed to build prediction functions that are valid throughout the study area, calibrating the coefficients on the basis of the real estate data contained on the supporting database. We also think about the possibility of implementing automated valuation methods in atypical markets, when lack of comparables occurs, implementing a Cost Approach procedure by integrating a BIM cost analysis into a GIS environment. The idea is to entrust the analysis of intrinsic characteristics to the fifth dimension of BIMs and that of extrinsic characteristics to the spatial analyses typical of GISs. In fact, the flow of information from the building model can be conveyed into a computerized database containing economic information about the location characteristics through the interoperability languages represented by the Industry Foundation Classes (IFC). In this way, a semi-automated valuation procedure can be implemented.

\subsection{The Cost Approach}

The Cost Approach aims to determine the value of a property based on the substitution principle: A buyer is not willing to spend more on a property than it would cost them to rebuild it, taking into account the state of depreciation. The use of this evaluation method derives from the following factors:

- Inability to use the market approach due to the absence or insufficiency of the sales data of the comparables;

- Uncertainty about the technical-economic parameters to be placed at the basis of financial evaluation procedures;

- Impossibility of hypothesizing a transformation into a property to be appreciated in the reference market;

- The Cost Approach appraises the value of a property through the sum of the value of the soil and the cost of reconstruction of the building (possibly depreciated):

$$
V=D R C+V_{s}=C-D+V_{s}
$$

where $D R C$ is the depreciated reproduction cost, $C$ is the reconstruction cost, $D$ is the depreciation, and $V_{S}$ is the value of the soil.

By cost $C$ is meant the set of expenses that an entrepreneur must incur to obtain an asset (manufactured). The cost is made up of various expense items, relating to the construction cost of 
structures, plants, and finishes, the arrangement of the external areas, the concession and urbanization costs, the technical costs, the financial interests, and the business profit [57].

The depreciated reconstruction cost is the cost referring to an existing or past building. To take into account the age of a property, it is important to apply the depreciation D that the property has accrued during its period of use to the cost of reconstruction. Properties are subjected to a depreciation process, that is, to a process of progressive loss of their intrinsic economic value. This depreciation is the result of the combination of three factors: physical deterioration, functional obsolescence, and economic obsolescence. Physical deterioration is the part of the depreciation of the real estate property owing to the deterioration of its building components (structures, finishes, plants) as a consequence of time and use (age). Functional obsolescence is the loss of value of a property caused by its inability to perform its functions effectively and efficiently for variable causes, such as changes in behavior patterns and, therefore, in users' requests or regulatory changes relating to their requirements and technical solutions. Economic obsolescence, on the other hand, derives from causes external to the property, relating to the location or conditions of the real estate market at the time of appraisal.

The literature reports criteria for appraising depreciation percentage. The Union Européenne des Expert Comptables Economiques et Financiers (U.E.C.) proposes a formula that calculates the depreciation percentage $D \%$, so that at $t=0$, the percentage depreciation is zero, while at the end of the economic life $(t=n)$, the percentage depreciation is $100 \%$ :

$$
D_{t}(\%)=\frac{\left(\frac{t}{n} \cdot 100+20\right)^{2}}{140}-2,86,
$$

The soil value expressed by $\mathrm{v}_{\mathrm{s}}$ is essentially related to consistence and location, and it has to be appraised as a possible consequence of the availability of data (usually through a market-oriented method).

Recalling the distinction between intrinsic and extrinsic characteristics, the DRC deals with the appraisal of the former, while the soil value includes the incidence of the latter.

The methodology proposed in this paper consists of entrusting the appraisal of the construction cost of the building to the 5D BIM, while it refers the valuation of the value of the soil to the GIS technology; the depreciation is taken into account in the semi-automated interoperability procedure.

\subsection{BIM and GIS Interoperability}

The sector of geographic information systems, hit by the rapid advancement towards 3D modeling, is in great turmoil. This evolution reflects the metamorphosis that the world of design and construction is experiencing in the transition from 2D to 3D building information modeling (BIM), and signals the growth of the integration between GIS and BIM in a single holistic environment.

While GIS information is required for planning and managing large-scale objects, BIM information is critical for the design and construction of such objects.

There are different software options for both GIS and BIM management. Some products are entirely free of cost; others provide free licenses to students and academic institutions or free trials for a limited period. Still others are paid. There is a wide range of free and open source software solutions, both for GIS platforms (QGIS, Grass, SAGA GIS, Mapwindow, etc.) and BIM ones (TeklaBIMsight, BIMx, DynamoBIM, SketchUP, etc.).

The real challenge lies in the integration between the two elements, which will allow a level of geospatial context to be integrated into the BIM model. Nowadays, there are no tools capable of creating a direct flow from one system to the other. Some software houses are collaborating to achieve better software interoperability for BIM and GIS, which can create the "digital twin" of a physical structure to allow better contextualized design in the real world, making both construction and use more efficient. 
At present, however, it is necessary to turn to procedures based on the use of interchange formats, such as the CityGML format, a GIS-related exchange format to store digital 3D models of cities and landscapes, and which, therefore, has a large-scale relapse, and the IFC one, a BIM-related exchange format intended to describe architectural, building, and construction industry data, so that it has a punctual reference.

The choice of one or the other format and of the interoperability procedures is made according to the software used and the purpose of the work.

GIS and BIM interoperability has been created for several purposes, such as urban policies [58], asset management [59], and infrastructures [60,61], while real estate valuation applications are few and fragmented, given the large amount of data necessary for the a real estate appraisal contained in the BIM, which, often, are lost in the exchange file.

\subsection{D BIM for Cost Reconstruction Quantification}

The appraisal of the reconstruction cost requires one to process a bill of quantity (BOQ). The appraiser first divides the project into BOQ items, which can also be called cost items based on the BOQ standard. Second, one calculates the quantity of the cost item. Third, one has to calculate the consumption of the construction resources for each cost item based on the national or local price list. Fourth, based on the prices of labor, material, and equipment in the market and the calculation rules of the overheads in the standard, one calculates the cost value of each cost item. Then, all the cost items are summarized to obtain the total cost of the project.

The benefits of using 5D BIM in construction processes consist of maximum control in cost analysis (every single detail is tracked and monitored, ensuring maximum calculation accuracy and accuracy cost control in construction companies), calculation speed (the compilation and calculation of data using BIM significantly accelerate each procedure, optimizing staff work times), and cost and staff savings( greater control, faster processing speed, and shorter working times translate into cost savings).

It is evident that the first step of the analysis consists of the punctual, precise, and accurate reconstruction of the 3D building in its physical and geometric components. The model alone just returns the list of quantities, but it is not able to do an appraisal. However, the idea of this work is that it is possible to reach a semi-automatic BOQ estimate in the BIM software by inserting information related to the unit prices of each category into the specifications of the used materials. In this way, the BIM model is able to return the BOQ appraisals for the different items (structural elements, floors, windows, doors, plant systems, etc.) through the option of total counts. These partial costs will then be read and processed by the GIS platform to calculate the total reconstruction cost and then the depreciated one, to be finally added to the soil value.

It should be emphasized that it may be convenient to define a construction model in which materials and related costs are defined, a model that can be reused for different buildings, provided that they fall within a homogeneous market context as regards the price list.

\subsection{GIS Platform for Depreciated Cost Quantification}

We know that geographic information systems allow not only spatial analysis, but also mathematical operations. This potential, combined with the presence of automating procedure tools, allows the reading and processing of the cost items transferred from the BIM model through the IFC format in order to quantify the total reconstruction cost.

To make this idea operational, we could use a computer procedure using an appropriate programming language or use the object-oriented programming tools available in GIS platforms in order to implement a procedure that is able to read the fields of the BIM model, to add the different cost items, and then to also consider the land value.

According to this aim, it is necessary to first create a computerized real estate database containing information relating to the value of the areas. To this end, it is necessary to prepare a thematic layer 
aimed at memorizing the real estate prices-for example, those of the Revenue Agency-and the related area incidence coefficients as reported in the official bulletins.

In this way, the automatic procedure could read the input data from the IFC model, process the information contained in the fields relating to the cost items, adding the soil value obtained by a spatial analysis, and, finally, returning the value of the property subject. Figure 1 represents a flow chart of the proposed methodology.

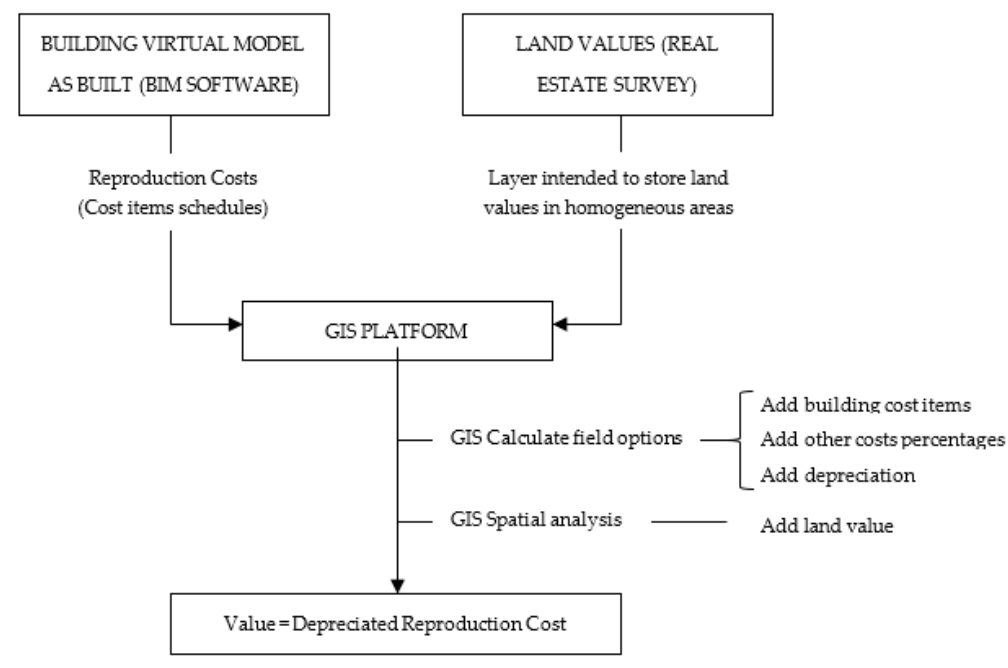

Figure 1. Methodology.

It remains to be underlined, however, that, as far as we know, the export of the IFC file to the ArcGIS platform is not yet optimal from a functional point of view, so not all fields of the 3D model are visible in the information system. For this reason, despite the belief that further developments are possible, in this work, the application is made possible by a semi-automatic procedure through an intermediate step carried out in an excel spreadsheet, as indicated in the case study.

\section{Case Study}

The described methodology was applied to a housing module located in the municipality of Rende, in the south of Italy, within the COGITO project "COGnitive dynamIc sysTem to allOw buildings to learn and adapt" conducted by the University of Calabria, Italy. The area includes a number of 1970s-style buildings intended for social housing (Figure 2). The basic module consists of two units (hereafter referred to as module A and Module B): a three-story building and a five-story building, connected by access ramps inserted between the buildings. The various blocks have been assembled in such a way as to have a curvilinear plan, while, in elevation, the facade is articulated by the alternation of different heights.
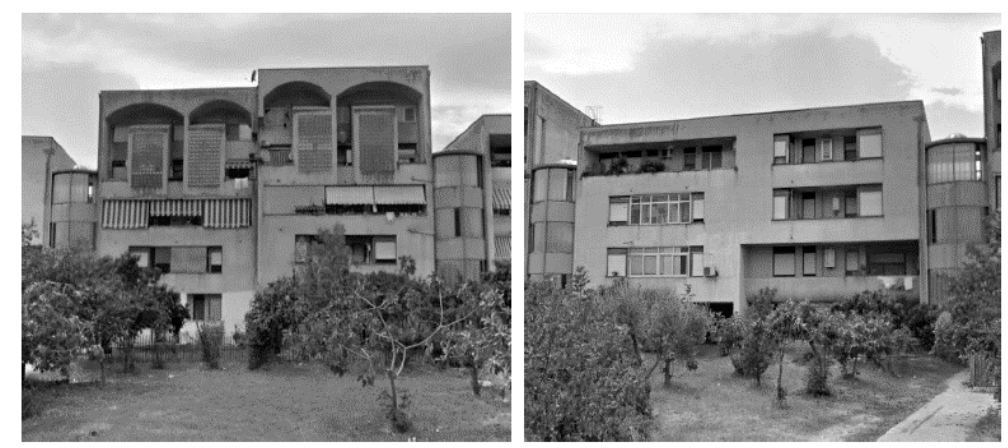

Figure 2. Basic modules. 
The subject property of the analysis is just one block (Module A), consisting of three floor levels and six apartments. It was implemented in a BIM model through the Revit software. It is a virtual model containing a series of information about geometry, materials, and bearing structure. In the implementation of the virtual model, the structural component was first recreated (Figure 3), followed by the architectural one (Figure 4 ).

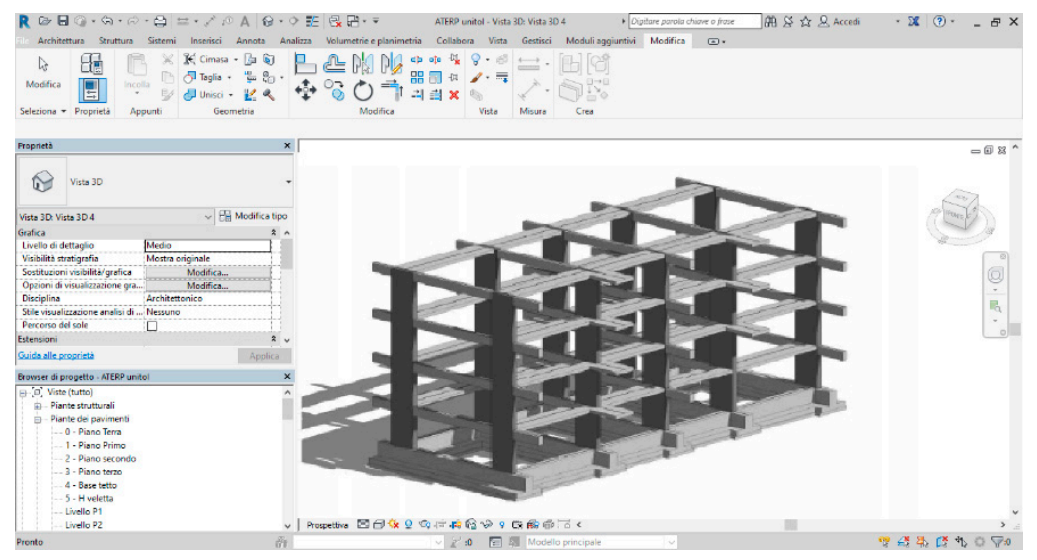

Figure 3. Structural component (Module A).

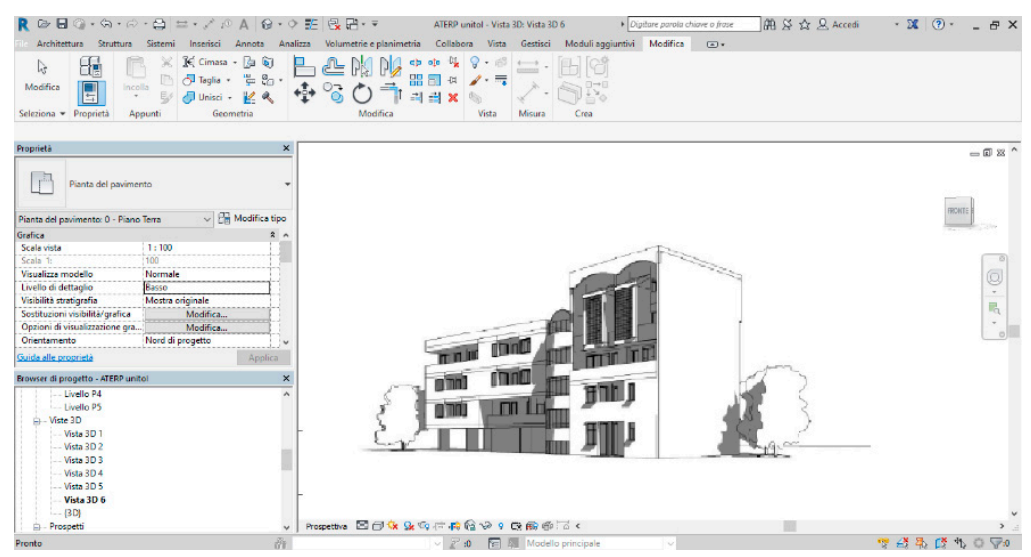

Figure 4. Architectural model (complete module $(\mathrm{A}+\mathrm{B})$ ).

As regards the structural component, the frame-consisting of pillars, beams, and foundationswas modeled, including a general indication about steel reinforcement.

Concerning the architectural component, all the objects were digitized as built: walls, floors, internal and external fixtures, ramps, and stairs. In particular, for a better insertion and a more pleasant graphic display, all the blocks of the building system were reconstructed.

Construction details, used materials, and related unit costs were specified for each of the architectural and structural objects. The unit costs were taken from the official price lists for the area under investigation (Calabria region price list 2017).

By activating the total counting options for a field specifically defined to store costs, the BIM software returns different quantity schedules relating to the components of the building, representing BOQ estimates for the different items (Table 1). The BIM software is not able to add the different cost components, but through the IFC interoperability format, it could transfer this disaggregated information to the GIS platform, and mathematical processing tools could manage it. 
Table 1. Bill of quantity (BOQ) estimate (EUR) for Module A.

\begin{tabular}{ccc}
\hline BOQ & \multicolumn{2}{c}{ Costs (EUR) } \\
\hline $\begin{array}{c}\text { pillars } \\
\text { concrete } \\
\text { steel } \\
\text { formwork }\end{array}$ & 7962.15 & \\
\hline beams & $10,512.91$ & \\
concrete & $20,314.82$ & $38,789.88$ \\
\hline $\begin{array}{c}\text { steel } \\
\text { formwork }\end{array}$ & $10,281.51$ & \\
\hline walls & $14,785.25$ & \\
\hline floors & $24,393.12$ & $49,459.88$ \\
\hline doors & & $170,190.16$ \\
\hline windows & $196,953.02$ \\
\hline sanitary installations & & $20,453.18$ \\
\hline technological systems & $56,755.00$ \\
\hline arrangement of outdoor areas & & $50,000.00$ \\
\hline & Total & $90,000.00$ \\
\hline
\end{tabular}

The BIM model was then exported into the GIS platform using ArcGIS software (Figures 5 and 6).

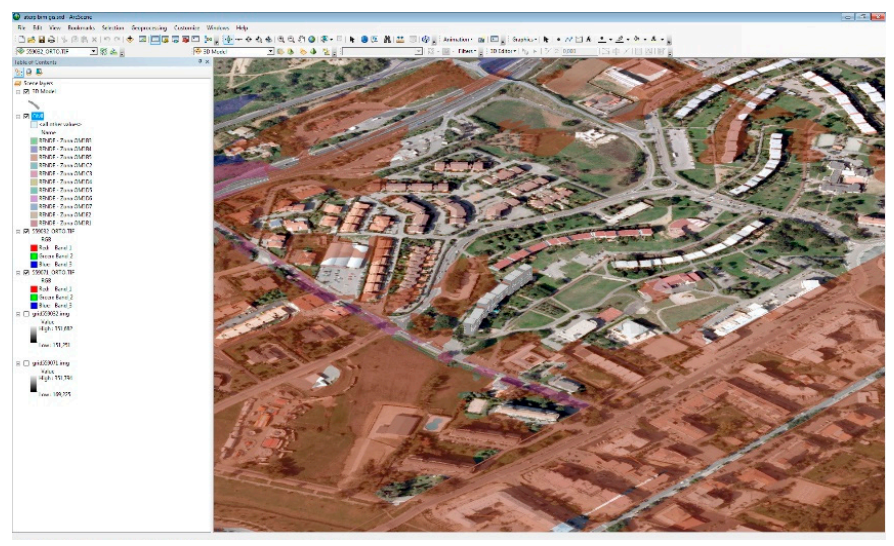

Figure 5. Case study location.

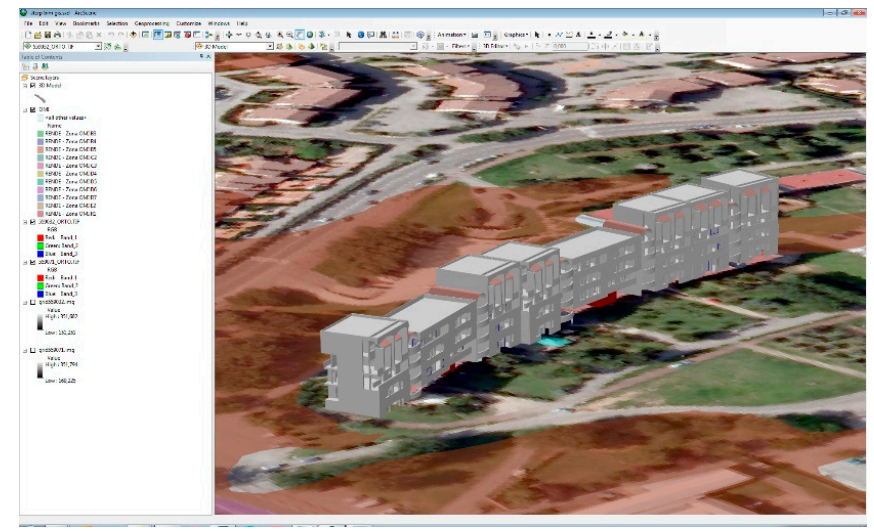

Figure 6. Building information model (BIM) in the global information system (GIS) platform (Modules $\mathrm{A}+\mathrm{B}$ in a curved assembly). 
In the GIS platform, the real estate database was previously built by acquiring information from the Revenue Agency (Figure 7, 2019 survey) [62]. In particular, land values were calculated in each homogeneous area using the area impact coefficient on real estate prices $(18 \%$ ratio, detected among real estate operators in the subject area) and by considering an area extension represented by the footprint area of the building (through an intersection tool).

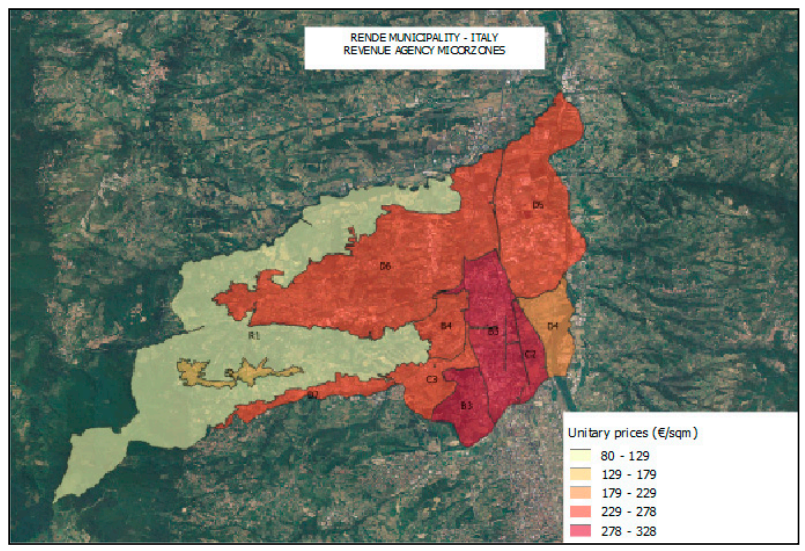

Figure 7. Land values in homogeneous microzones-Revenue Agency 2019.

The procedure would have to read the building costs, to add all other percentage costs, and, finally, to also consider a depreciation factor. According to the building location, the procedure would have to add to the aforementioned costs and the land area incidence taken from the real estate database.

Considering that the GIS platform is not yet able to read all 3D IFC fields, including those relating to the cost fields, from an operational point of view, the interoperability between the BIM and the GIS was carried out with the aid of an Excel file. All of the schedules of quantities were exported and calculated in a BOQ software (ACR Win by STS) and then reported in an Excel spreadsheet. The table relating to the calculation of the land value was exported to the same spreadsheet, and the procedure for the effective sum of the contributions was implemented inside it, obtaining what reported in Table 2 .

Table 2. Depreciated reconstruction cost (EUR)-Module A.

\begin{tabular}{cc}
\hline Reproduction Cost & $706,231.18$ \\
\hline concessor and urbanization charges (5\%) & $35,311.56$ \\
technical and general expenses (7\%) & $49,436.18$ \\
financial interests (2\%) & $15,819.58$ \\
business profit (15\%) & $105,934.68$ \\
total & $912,733.18$ \\
depreciation \% (construction date 1975) & 0.27 \\
depreciated cost & $666,295.22$ \\
land value (mq 204) & $102,000.00$ \\
total value & $768,295.22$ \\
\hline
\end{tabular}

\section{Possible Future Developments: The Role of Structural Health Monitoring (SHM) and IoT in Preserving the Economic Value of the Building}

Until the recent past, safety and structural efficiency were assessed episodically. The checks should have been scheduled periodically. This was true enough for the most important infrastructures, such as bridges, dams, and public buildings of significant strategic importance, such as hospitals, although recent tragic events, such as the collapse of the Morandi bridge in Genoa, have often contradicted this consideration [63].

For private buildings, which are almost always used for residential purposes, everything has been left, at least in Italy, to the goodwill of the owners, who, however, having no specific skills related 
to resistance and structural efficiency, have rarely understood the importance of periodic checks of "structural health"; these have been limited to checks only after significant events, such as earthquakes, and only if they noticed cracks or other worrying phenomena.

In recent decades, Italian legislators have attempted the compulsory or "almost compulsory" introduction of so-called "building files", in which all significant changes from a structural point of view had to be reported by specialized technicians in order to guarantee safety for those who used the building itself, but also to stimulate more stringent and better-scheduled checks on the ages of materials and structures, on the consequences of phenomena such as seismic events, and, in any case, on fatigue phenomena, which are often imperceptible in the short term but dangerous in the long term.

Recently, also following disastrous events on many road and railway infrastructures, the idea of continuous monitoring of structural health has made progress. This was also favored by the development of a series of possibilities on various fronts of the Internet of Things (IoT), structural sensors, and SAR interferometry [64]. In particular, electronic engineering has provided sensors for the continuous measurement of various quantities, such as accelerations, temperatures, inclinations, displacements, etc., while computational mechanics has provided increasingly sophisticated software to analyze the structural behavior of an undamaged structure and of a damaged one, also with inverse methods, which, starting from the experimental results, that is, from the data provided by the sensors, provide the variation in resistance and, therefore, any damage to the structure. The determination of the geometry of the structure has also been simplified in the survey methods and made more precise by new instruments, such as laser scanners, satellite surveys, etc.

In practice, the combination of innovative sensors, structural software, improved geometric measurements, and new telecommunication modes (such as wireless networks, ADSL, satellite transmissions, the Internet network, etc.) has produced the birth of a new branch of structural engineering, closely connected to the IoT, which takes the name of "Structural Health Monitoring" (SHM).

As mentioned, this new section of structural engineering has almost always involved bridges, viaducts, and large infrastructures. In a recent work, Zinno et al. [65] demonstrated the possibility of extending SHM to buildings, and made a prototype for a school in the province of Cosenza (Italy), the "Monaco" Industrial Technical Institute of Cosenza. Based on experience gained in structural analysis with the finite element method [66], innovative materials [67], and innovative relief techniques [68], by integrating them with the new IoT methods, the authors applied instruments to a part of the building, allowing the structural health status to be known in real time, highlighting a significant change (beyond a predetermined tolerance) of the dynamic behavior of the structure (in practice, evaluating in real time the main frequencies and the main modes of vibration), thus obtaining the possibility of producing an alert for competent authorities about any dangerous structural damage, or even to inform the owner of changes that require further diagnostics or maintenance. Recently, the research team has been working on the possibility of making the building "cognitive", or predicting the remaining life of the building, but, above all, allowing maintenance planning, thus extending the useful life of the building up to the maximum limit allowed by the materials and structural types used. This appears possible by integrating two other modern tools: building information modeling (BIM), already described in this paper, and artificial intelligence (AI), particularly by using artificial neural networks (ANNs) and genetic algorithms (GAs) [69]. From the perspective of future research, it will also be important to evaluate the use of the broader terms of machine learning and of deep convolutional networks.

It is easy to understand, therefore, that being able to guarantee structural safety in real time, both by promoting an early warning and by promoting planned maintenance of the building, adds economic value to it, which is hoped to be increasingly taken into consideration by civil society. Preserving the efficiency of a building is clearly an economic benefit [70] that a correct economic evaluation cannot neglect, not to mention that reducing the danger of loss of life has an invaluable economic value. This paragraph, therefore, intends to represent the tracing of future development 
of the topic treated here to also include the significance of the economic importance of the SHM in connection with the IoT, with BIMs, and with the AI of ANNs and of GAs.

\section{Conclusions}

A livable city operates simultaneously on two levels: a physical one and a virtual one. The use of technologies allows a harmonic management of its services. Among these, an important service can be offered by the real estate sector, which can provide tools for different purposes, from taxation to private use (granting bank loans, real estate sales, etc.).

The real estate sector has always been a conservative one, often affected by a subjective approach, more often in viscous and atypical markets. The need to objectify real estate valuation as required by the International Valuation Standards has found concrete possibilities to experiment thanks to the use of information technologies. This approach has led to the implementation of so-called automatic valuation methods which, normally implemented on GIS platforms, are frequently based on the application of multiple regression models in the context of procedures based on market supply. This type of approach, however, is not applicable in atypical markets, where it is difficult to detect an adequate amount of sales data.

This paper proposes the possibility of extending the field of applicability of automatic valuation methods to complex and viscous real estate markets by using the valuation methods recommended in these circumstances, such as the Cost Approach.

From this perspective, the novelty of the research idea, which is essentially one for real estate appraisal, concerns the extension of the available web-based automated property valuation to valuation methods that are different from the market-oriented ones, always according to the International Valuation Standards, while the real operational challenge is to integrate information technologies represented by building information modeling and geographic information systems into the fields of construction and infrastructure. The idea is to entrust a BIM with the estimation of intrinsic characteristics while a GIS deals with the estimation of the location components.

From a conceptual point of view, the interoperability between the two software tools can be carried out through the IFC interchange file, and the BOQ estimate can be resolved without the aid of external software, but simply by turning to the potential of the two IT tools.

The case study shows some difficulties in the operational terms because of the loss of information in the IFC model, requiring one to use a different way for interoperability.

Future research will focus on the deepening of the case study on an operational level in order to perfect the automation of interoperability by building a software architecture to integrate data transmission between the different systems and to test appropriate verification tools, pending improvement in the ICF model's reading system.

If real estate evaluation bases its validity on the availability and quality of information as well as how sharable it is, information technologies are the most concrete and fruitful perspective in appraisal research, even where a systematic, rational, objective, and automatic valuation approach seems difficult to apply.

Author Contributions: This paper is to be attributed in equal parts to the four authors. All authors have read and agreed to the published version of the manuscript.

Funding: This research received a funding from the project ARS01_00836 COGITO_COGnitive dynamIc sysTem to allow buildings to learn and adapt, University of Calabria, Italy

Conflicts of Interest: The authors declare no conflict of interest. 


\section{References}

1. Bevilacqua, P.; Bruno, R.; Arcuri, N. Green roofs in a Mediterranean climate: Energy performances based on in-situ experimental data. Renew. Energy 2020, 152, 1414-1430. [CrossRef]

2. Maiolo, M.; Pirouz, B.; Bruno, R.; Palermo, S.A.; Arcuri, N.; Piro, P. The role of the extensive green roofs on decreasing building energy consumption in the mediterranean climate. Sustainability 2020, 12, 359. [CrossRef]

3. Quan, D.C.; Quigley, J.M. Price formation and the appraisal function in real estate markets. J. Real Estate Financ. Econ. 1991, 4, 127-146. [CrossRef]

4. Simonotti, M. Metodi di Stima Immobiliare; DarioFlaccovio: Palermo, Italy, 2006.

5. Carpino, C.; Bruno, R.; Arcuri, N. Social housing refurbishment in Mediterranean climate: Cost-optimal analysis towards the n-ZEB target. Energy Build. 2018, 174, 642-656. [CrossRef]

6. Venkatachalam, L. The contingent valuation method: A review. Environ. Impact Assess. Rev. 2004, $24,89-124$. [CrossRef]

7. Hicks, J.R. The four consumer's surpluses. Rev. Econ. Stud. 1943, 11, 31-41. [CrossRef]

8. Mitchell, R.C.; Carson, R.I. Using Surveys to Value Public Good. The Contingent Valuation Method; Resources for the Future: Washington, DC, USA, 1989.

9. Aranda-Mena, G.; Crawford, J.; Chevez, A.; Froese, T. Building information modelling demystified: Does it make business sense to adopt BIM? Int. J. Manag. Proj. Bus. 2009. [CrossRef]

10. Hardin, B.; McCool, D. BIM and Construction Management: Proven Tools, Methods, and Workflows; John Wiley \& Sons: Hoboken, NJ, USA, 2009.

11. Shenkel, W.; Eidson, A. Comparable sales retrieval systems. Apprais. J. 1971, 31, 540-544.

12. Dilmore, G. Appraising houses. Real Estate Appraiser 1974, 40, 21-32.

13. Detweiler, J.; Radigan, R. Computer-assisted real estate appraisal. Apprais. J. 1996, 64, 91-101.

14. Detweiler, J.; Radigan, R. Computer-assisted real estate appraisal: A tool for the practicing appraiser. Apprais. J. 1999, 67, 280-286.

15. Del Giudice, V.; Manganelli, B.; De Paola, P. Spline smoothing for estimating hedonic housing price models. In Proceedings of the 15th International Conference on Computational Science and its Applications 2015, LNCS, Banff, AB, Canada, 22-25 June 2015; Gervasi, O., Murgante, B., Misra, S., Gavrilova, M.L., Alves Coutinho Rocha, A.M., Torre, C., Taniar, D., Apduhan, B.O., Eds.; Springer: Heidelberg, Germany, 2015; Volume 9157, pp. 210-219.

16. Manganelli, B.; De Mare, G.; Nesticò, A. Using genetic algorithms in the housing market analysis. In Proceedings of the 15th International Conference on Computational Science and its Applications 2015, LNCS, Banff, AB, Canada, 22-25 June 2015; Gervasi, O., Murgante, B., Misra, S., Gavrilova, M.L., Alves Coutinho Rocha, A.M., Torre, C., Taniar, D., Apduhan, B.O., Eds.; Springer: Heidelberg, Germany, 2015; Volume 9157, pp. 36-45.

17. Tajani, F.; Morano, P.; Locurcio, M.; D'Addabbo, N. Property valuations in times of crisis. Artificial neural networks and evolutionary algorithms in comparison. In Proceedings of the 15th International Conference on Computational Science and its Applications 2015, LNCS, Banff, AB, Canada, 22-25 June 2015; Gervasi, O., Murgante, B., Misra, S., Gavrilova, M.L., Alves Coutinho Rocha, A.M., Torre, C., Taniar, D., Apduhan, B.O., Eds.; Springer: Heidelberg, Germany, 2015; Volume 9157, pp. 194-209.

18. Fik, T.; Ling, D.; Mulligan, G. Modeling spatial variation in housing prices: A variable interaction approach. Real Estate Econ. 2003, 31, 623-646. [CrossRef]

19. Dubin, R. Estimation of regression coefficients in the presence of spatially autocorrelated error terms. Rev. Econ. Stat. 1998, 70, 466-474. [CrossRef]

20. Manganelli, B.; Pontrandolfi, P.; Azzato, A.; Murgante, B. Using geographically weighted regression for housing market segmentation. Int. J. Bus. Intell. Data Min. 2014, 9, 161-177. [CrossRef]

21. O'Connor, P. Automated valuation models by model-building practitioners: Testing hybrid model structure and GIS location adjustments. J. Prop. Tax Assess. Adm. 2008, 5, 5-24.

22. Goodman, A.; Thibodeau, T. The spatial proximity of metropolitan area housing submarkets. Real Estate Econ. 2007, 35, 209-232. [CrossRef]

23. Bourassa, S.; Cantoni, E.; Hoesli, M. Spatial dependence, housing submarkets, and house price predictions. J. Real Estate Financ. Econ. 2007, 35, 143-160. [CrossRef] 
24. Borst, R.; McCluskey, W. The modified comparable sales method as the basis for a property tax valuations system and its relationship and comparison to spatially autoregressive valuation models. In Mass Appraisal Methods: An International Perspective for Property Valuers; Kauko, T., d'Amato, M., Eds.; Wiley Blackwell: Chichester, UK, 2008; pp. 49-69.

25. Case, B.; Clapp, J.; Dubin, R.; Rodriguez, M. Modeling spatial and temporal house price patterns: A comparison of four models. J. Real Estate Financ. Econ. 2004, 29, 167-191. [CrossRef]

26. Pace, R.; Gilley, O. Generalizing the OLS and grid estimators. Real Estate Econ. 1998, 1, 331-346. [CrossRef]

27. Bourassa, S.; Cantoni, E.; Hoesli, M. Predicting house prices with spatial dependence: A comparison of alternative methods. J. Real Estate Res. 2010, 32, 139-159.

28. Bourassa, S.; Cantoni, E.; Hoesli, M. Robust repeat sales indexes. Real Estate Econ. 2013, 41, 517-554. [CrossRef]

29. Ciuna, M.; De Ruggiero, M.; Salvo, F.; Simonotti, M. Automatic Research of the Capitalization Rate for the Residential Automated Valuation: An Experimental Study in Cosenza. In Advances in Automated Valuation Modeling. AVM After the Non-Agency Mortgage Crisis; d'Amato, M., Kauko, T., Eds.; Springer: Heidelberg, Germany, 2017; pp. 361-380.

30. Ciuna, M.; De Ruggiero, M.; Salvo, F.; Simonotti, M. Automated Procedures Based on Market Comparison Approach in Italy. In Advances in Automated Valuation Modeling. AVM After the Non-Agency Mortgage Crisis; d'Amato, M., Kauko, T., Eds.; Springer: Heidelberg, Germany, 2017; pp. 381-400.

31. Ciuna, M.; De Ruggiero, M.; Manganelli, B.; Salvo, F.; Simonotti, M. Automated valuation methods in atypical real estate markets using the mono-parametric approach. In Proceedings of the International Conference on Computational Science and Its Applications; Springer: Cham, Switzerland, 2017; pp. 200-209.

32. Brankovic, S. Real estate mass appraisal in the real estate cadaster and GIS environment. Geod. List 2013, 67, 119-134.

33. Bateman, I.J.; Jones, A.P.; Lovett, A.A.; Lake, I.R.; Day, B.H. Applying geographical information systems (GIS) to environmental and resource economics. Environ. Resour. Econ. 2020, 22, 219-269. [CrossRef]

34. Rodriguez, M.; Sirmans, C.; Marks, A. Using geographic information systems to improve real estate analysis. J. Real Estate Res. 1995, 10, 163-173.

35. Sarip, A.G. Integrating artificial neural networks and GIS for single-property valuation. In Proceedings of the Elevation-PRRES Conference, Pacific Rim Real Estate Society, Citeseer, Melbourne, Australia, 23-27 January 2005.

36. Demetriou, D. GIS-based automated valuation models (AVMs) for land consolidation schemes. In Proceedings of the 6th International Conference on Cartography and GIS, Albena, Bulgaria, 13-17 June 2016; pp. 43-51.

37. García, N.; Gámez, M.; Alfaro, E. ANN+ GIS: An automated system for property valuation. Neurocomputing 2008, 71, 733-742. [CrossRef]

38. Droj, L.; Droj, G. Considerations Regarding Valuation of Private Properties Using the Automated Valuation Models Based on Gis. Ann. Univ. Oradea 2015, 380-388.

39. Olatunji, O.A.; Sher, W.D.; Ogunsemi, D.R. The Impact of Building Information Modelling on Construction Cost Estimation. In Proceedings of the 18th CIB World Building Congress, Salford, UK, 10-13 May 2010.

40. Lu, W.; Fung, A.; Peng, Y.; Liang, C.; Rowlinson, S. Cost-benefit analysis of Building Information Modeling implementation in building projects through demystification of time-effort distribution curves. Build. Environ. 2014, 82, 317-327. [CrossRef]

41. Isikdag, U.; Underwood, J. Two design patterns for facilitating Building Information Model-based synchronous collaboration. Autom. Constr. 2010, 19, 544-553. [CrossRef]

42. Ashworth, A. Cost Studies of Building; Pearson Education Limited: Essex, UK, 2004.

43. Cartlidge, D. Quantity Surveyor's Pocket Book; Butterworth-Heinemann: Oxford, UK, 2009.

44. Eastman, C.; Teicholz, P.; Sacks, R.; Liston, K. BIM Handbook: A Guide to Building Information Modeling; John Wiley \& Sons: Hoboken, NJ, USA, 2011.

45. Jiang, X. Developments in Cost Estimating and Scheduling in BIM Technology. Master's Thesis, Northeastern University, Boston, MA, USA, 2011.

46. Wu, S.; Wood, G.; Ginige, K.; Jong, S.W. A technical review of BIM based cost estimating in UK quantity surveying practice, standards and tools. J. Inf. Technol. Constr. 2014, 19, 534-562.

47. Kehily, D.; Underwood, J. Embedding life cycle costing in 5D BIM. J. Inf. Technol. Constr. 2017, 22, 145-167. 
48. Marzouk, M.; Azab, S.; Metawie, M. BIM-based approach for optimizing life cycle costs of sustainable buildings. J. Clean. Prod. 2018, 188, 217-226. [CrossRef]

49. Nour, M.; Hosny, O.; Elhakeem, A. A BIM based energy and lifecycle cost analysis/optimization approach. Int. J. Eng. Res. Appl. 2012, 2, 411-418.

50. Redmond, A.; Hore, A.V.; West, R. Developing a cloud integrated life cycle costing analysis model through BIM. In Proceedings of the Computer Knowledge Building, Sophia Antipolis, France, 26-28 October 2011. [CrossRef]

51. El Yamani, S.; Ettarid, M.; Hajji, R. Building Information Modeling Potential for an enhanced real estate valuation approach based on the hedonic method. Wit Trans. Built Environ. 2019, 192, 305-316.

52. Yu, H.; Liu, Y. Integrating Geographic Information System and Building Information Model for Real Estate Valuation. In Proceedings of the FIG Working Week 2016, Christchurch, New Zealand, 2-6 May 2016.

53. Forte, C.; De Rossi, B. Principi di Economia e di Estimo; Etas: Milano, Italia, 1974.

54. Realfonzo, A. Teoria e Metodo Dell'estimo Urbano; Nis: Roma, Italia, 1994.

55. Roscelli, R. Manuale di Estimo; UTET Università, Novara: Milano, Italia, 2014.

56. Pagourtzi, E.; Assimakopoulos, V.; Hatzichristos, T.; French, N. Real estate appraisal: A review of valuation methods. J. Prop. Invest. Financ. 2003, 21, 383-401. [CrossRef]

57. Calabrò, F.; Della Spina, L. Processo edilizio e stima dei costi. LaborEst 2005, 11, 12-21.

58. Barbato, D.; Pristeri, G.; De Marchi, M. GIS-BIM Interoperability for Regeneration of Transurban Areas. In Proceedings of the 23rd International Conference on Urban Planning, Regional Development and Information Society, REAL CORP 2018: EXPANDING CITIES-DIMINISHING SPACE Are "Smart Cities" the solution or part of the problem of continuous urbanisation around the globe?", Vienna, Austria, 4-6 April 2018; pp. 243-250.

59. Zhang, X.; Arayici, Y.; Wu, S.; Abbott, C.; Aouad, G.F. Integrating BIM and GIS for large-scale facilities asset management: A critical review. In Proceedings of the Twelfth International Conference on Civil, Structural and Environmental Engineering Computing, Funchal, Madeira, Portugal, 1-4 September 2009.

60. Vilgertshofer, S.; Amann, J.; Willenborg, B.; Borrmann, A.; Kolbe, T.H. Linking BIM and GIS models in infrastructure by example of IFC and CityGML. Comput. Civ. Eng. 2017, 2017, 133-140.

61. Marzouk, M.; Othman, A. Planning utility infrastructure requirements for smart cities using the integration between BIM and GIS. Sustain. Cities Soc. 2020, 57, 102120. [CrossRef]

62. Revenue Agency. Available online: https://www.agenziaentrate.gov.it/portale/schede/fabbricatiterreni/omi/ banche-dati/quotazioni-immobiliari (accessed on 28 May 2020).

63. Morgese, M.; Ansari, F.; Domaneschi, M.; Cimellaro, G.P. Post-collapse analysis of Morandi's Polcevera viaduct in Genoa Italy. J. Civ. Struct. Health Monit. 2020, 10, 69-85. [CrossRef]

64. Zhu, M.; Wan, X.; Fei, B.; Qiao, Z.; Ge, C.; Minati, F.; Vecchioli, F.; Li, J.; Costantini, M. Detection of building and infrastructure instabilities by automatic spatiotemporal analysis of satellite SAR interferometry measurements. Remote Sens. 2018, 10, 1816. [CrossRef]

65. Zinno, R.; Artese, S.; Clausi, G.; Magarò, F.; Meduri, S.; Miceli, A.; Venneri, A. Structural Health Monitoring (SHM), Internet of Things 2019; Springer Nature: Cham, Switzerland, 2019; pp. 225-249.

66. Zinno, R.; Barbero, E.J. A three-dimensional layer-wise constant shear element for general anisotropic shell-type structures. Int. J. Numer. Methods Eng. 1994, 37, 2445-2470.

67. Bruno, D.; Lato, S.; Zinno, R. Nonlinear analysis of doubly curved composite shells of bimodular material. Compos. Eng. 1993, 3, 419-435. [CrossRef]

68. Artese, S.; Achilli, V.; Zinno, R. Monitoring of bridges by a laser pointer: Dynamic measurement of support rotations and elastic line displacements: Methodology and first test. Sensors 2018, 18, 338. [CrossRef] [PubMed]

69. Gomes, G.F.; Mendez, Y.A.D.; Alexandrino, P.D.S.L.; Da Cunha, S.S.; Ancelotti, A.C. A review of vibration based inverse methods for damage detection and identification in mechanical structures using optimization algorithms and ANN. Arch. Comput. Methods Eng. 2019, 26, 883-897. [CrossRef]

70. Prizzon, F. Gli Investimenti Immobiliari; Celid: Torino, Italy, 1995.

(C) 2020 by the authors. Licensee MDPI, Basel, Switzerland. This article is an open access article distributed under the terms and conditions of the Creative Commons Attribution (CC BY) license (http://creativecommons.org/licenses/by/4.0/). 